\title{
Cross-cultural Adaptation of the Dysfunctional Voiding Score Symptom (DVSS) Questionnaire for Brazilian Children
}

\author{
Adriano A. Calado, Eleazar M. Araujo, Ubirajara Barroso Jr., Jose M. Bastos Netto, Miguel \\ Zerati Filho, Antonio Macedo Jr., Darius Bagli, Walid Farhat
}

Division of Pediatric Urology (AAC, EMA), Pernambuco State University, Recife, Pernambuco, Brazil, Division of Pediatric Urology (UBJ), Federal University of Bahia, Salvador, Brazil, Division of Pediatric Urology (JMBN), Federal University of Juiz de Fora, Minas Gerais, Brazil, Division of Pediatric Urology (MZF), Urology and Nephrology Institute, Sao Jose do Rio Preto, SP, Brazil, Division of Pediatric Urology (AMJ), Federal University of Sao Paulo, Sao Paulo, Brazil and Division of Pediatric Urology (DB, WF), Hospital for Sick Children, Toronto, Canada

\begin{abstract}
Purpose: To translate and culturally adapt the Dysfunctional Voiding Symptom Score (DVSS), questionnaire into Brazilian Portuguese.

Materials and Methods: The 10-item Dysfunctional Voiding Symptom Score (DVSS) was translated into Brazilian Portuguese according to a standard methodology: translation, synthesis, back-translation, Expert Committee, and pre-testing. After the translation process the final version was pre-tested and patient responses were analyzed to identify necessary modifications. Reliability was evaluated using the test-retest method, and internal consistency was assessed using Cronbach's alpha.

Results: The Cronbach's alpha coefficient was calculated in the test and retest phases. Internal consistency was found to be satisfactory, as confirmed by a Cronbach's alpha coefficient of 0.76 for the test and 0.77 for the retest. A high degree of stability was found in the test/retest, with an intraclass correlation coefficient (ICC) of 0.960 (p < 0.001; 95\% CI: 0.9430.972).

Conclusions: The cross-cultural adaptation process of the Dysfunctional Voiding Symptom Score questionnaire to be used on Brazilian children was successfully completed following internationally accepted methodologies.
\end{abstract}

Key words: urinary bladder; urinary incontinence; questionnaires; urinary tract infection Int Braz J Urol. 2010; 36: 458-63

\section{INTRODUCTION}

Dysfunctional voiding (DV) is a common clinical problem seen in approximately $40 \%$ of patients presenting to the pediatric urologist (1). Females are predominantly affected with a femaleto-male ratio of $5: 1(1,2)$. It is characterized by numerous symptoms, including recurrent urinary tract infections, urinary incontinence, constipation and encopresis. It is learned behavior that suppresses bladder contractions by inappropriately contracting the pelvic floor muscles (external urinary sphincter) during urination. This eventually becomes an involuntary process, resulting in functional obstruction of the urinary stream during voiding (detrusor/external urinary sphincter incoordination) (3).

The Standardization Committee of the International Children's Continence Society (4) defined 
dysfunctional voiding as "over activity of the urethral sphincter during the voiding contraction of the detrusor in neurologically normal children". There exists great variability in the clinical presentation of voiding dysfunction in children. This variability translates into different approaches for defining the problem and even treatment modalities. Although behavioral modification remains the cornerstone of treatment, pharmacological and biofeedback techniques have been used (5).

The various treatment outcome data published for pediatric dysfunctional voiding are difficult to compare secondary to the lack of a universally accepted reproducible means of reporting symptoms and improvement. Urologists are familiar with symptom scorings. The International Prostate Symptom Score has been widely accepted and is currently the most popular way of grading benign prostatic hyperplasia symptoms in men.

Farhat et al. (6) described validated symptom scoring for wetting and functional disorders in children called the dysfunctional voiding symptom score (DVSS). The DVSS includes 10 quantitative and qualitative urological variables assessed by age-appropriate questions for children, and has been used as an objective instrument to grade voiding dysfunction in children (Appendix-1).

Since this instrument was originally written in English and no similar validated questionnaire about this theme existed in Brazil, a cultural adaptation was necessary.

The cross-cultural adaptation process had to follow international guides to maintain the equivalence between the original and target versions $(7,8)$.

The aim of the present study was to translate and culturally adapt the questionnaire entitled Dysfunctional Voiding Symptom Score into BrazilianPortuguese language.

\section{MATERIALS AND METHODS}

Permission to translate the DVSS into Brazilian Portuguese was obtained from one of the DVSS's authors, Dr. Walid Farhat. The translation of this phase was carried out according to methods recommended in the literature (Figure-1). The translation of the instrument into Brazilian Portuguese was done independently by two Brazilians translators, who knew the study's objectives. The two Portuguese versions generated one version after authors' consensus (DVSS 1) and then, it was submitted to back-translation, done by two other translators, natives of the USA and England, who lived in Brazil, had full mastery of Portuguese and knowledge about Brazilian culture. The translators were neither informed about the study objectives, nor about the concepts involved and the goal of the instrument. The result of this phase was the DVSS version 2.

Subsequently, it that was submitted to a committee of experts, composed of 5 pediatric urology specialists, with English as their first language. They compared each item of the original instrument and the translated version in relation to semantic/idiomatic equivalences in order to assure the correct translation. Also, they had to assure the cultural equivalence, which is related to the context and the life experiences in Brazilian population, and conceptual equivalence, which is the verification of the original instrument concept maintenance in the translated version. The questionnaire items were considered as a good agreement by the Committee only when the agreement percentage was approximately $90 \%$.

For the qualitative analysis, a discussion about the judges' suggestions was performed. The goal was to consolidate all the versions of the instrument and indicate which characteristics should be considered in the pre-final version. A consensus was reached achieving semantic, idiomatic, experiential, and conceptual equivalence. After all suggestions made by the judges, the pre-final version was developed for field testing.

A pre-test was carried out to verify the cultural adequacy of the instrument, and the answer "I didn't understand the question" was added to all of the items. Data collection was conducted with 40 children who answered the instrument. Pre-test data analysis showed that none of the items was above the 15 th percentile of incomprehension, which attested to the instrument's adequacy with no need for changes to its content or a new pre-test.

After the conclusion of the pre-test, the final Brazilian-Portuguese version was obtained. The primary developer of the DVSS (Dr. Walid Farhat) was informed at all stages of the translation process and 


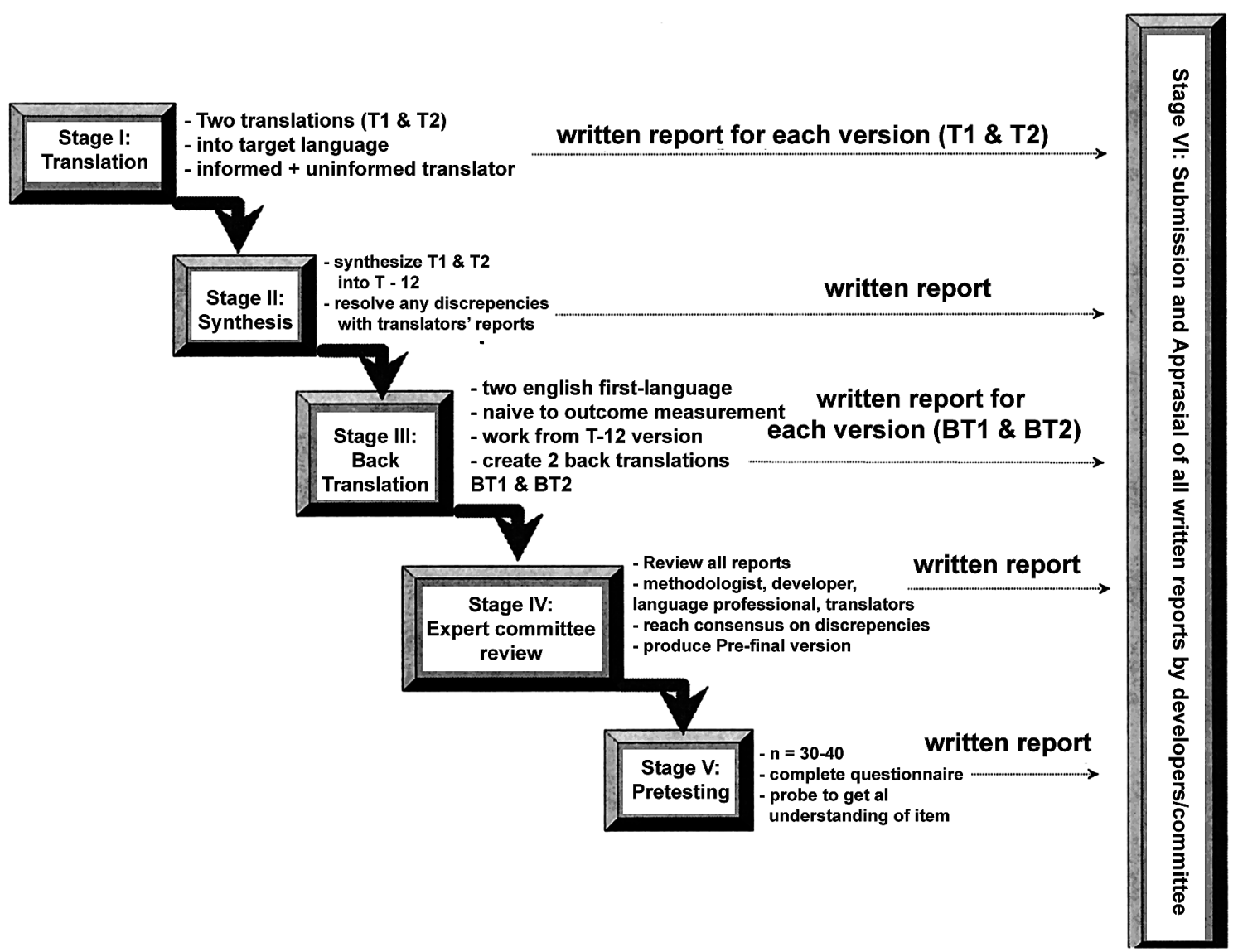

Figure 1 - Graphic representation of the stages of cross-cultural adaptation recommended.

approved the final version of the questionnaire and from now on will be referred to as the DVSS Brazilian version.

All patients who participated in this study were asked to provide written informed consent prior to enrollment. The full protocol received the approval of the Local Ethics and Research Committee.

The questionnaire data were recorded in commercial statistical software (Excel/2003 for Microsoft Windows). Descriptive statistics were used to describe the sample, to verify the content validity of the adapted instrument, and to determine the pretest results the following analyses were performed:

- Cronbach's coefficient alpha: to verify reliability. Cronbach alpha values $>0.70$ were established as constituting evidence of satisfactory internal consistency.

- Intraclass correlation coefficient (ICC): used to verify reliability with reference to the stability of the instrument (test-retest). ICC values $\geq 0.90$ were considered evidence of stability.

\section{RESULTS}

The team of specialists which analyzed the translations pointed out that there was a correspondence between the items translated, semantic equivalence between the two translations and no translation difficulty. Adjustments were made for the few verbal differences. Therefore, the counter-translation compared to the original version did not did not require any changes in grammatical structure, when the Portuguese version was translated back into English.

In the pretest phase, the questionnaire was answered by a sample of 40 parents of children with dysfunctional voiding symptoms. This group was characterized by the fact that the majority of subjects 
were female $(80 \%, 32 / 40)$ with a mean age of 6.2 years. Following application of the instrument, the patients were interviewed to evaluate the difficulties found in filling out the questionnaire and to identify any questions or words that were difficult to understand.

The Cronbach's alpha coefficient was calculated in the test and retest phases. Internal consis- tency was found to be satisfactory, as confirmed by a Cronbach's alpha coefficient of 0.76 for the test and 0.77 for the retest. A high degree of stability was found in the test/retest, with an intraclass correlation coefficient (ICC) of 0.960 ( $p<0.001 ; 95 \% \mathrm{CI}$ : 0.943-0.972). Table-1 presents the final version of the Brazilian DVSS.

Table 1 - Portuguese Brazilian version of the Dysfunctional Voiding Symptom Score.

\begin{tabular}{|c|c|c|c|c|}
\hline Durante os Últimos 30 Dias & $\begin{array}{c}\text { Nunca } \\
\text { ou } \\
\text { Quase } \\
\text { Nunca }\end{array}$ & $\begin{array}{c}\text { Menos } \\
\text { Que } \\
\text { Metade do } \\
\text { Tempo }\end{array}$ & $\begin{array}{l}\text { A Metade } \\
\text { do Tempo }\end{array}$ & $\begin{array}{l}\text { Quase } \\
\text { Todo o } \\
\text { Tempo }\end{array}$ \\
\hline 1. Seu(a) filho(a) tem molhado de xixi a roupa durante o dia? & 0 & 1 & 2 & 3 \\
\hline $\begin{array}{l}\text { 2. Quando seu(a) filho(a) se molha de xixi, a cueca ou calcinha } \\
\text { fica ensopada? }\end{array}$ & 0 & 1 & 2 & 3 \\
\hline $\begin{array}{l}\text { 3. Com que frequência seu(a) filho(a) não faz cocô } \\
\text { todos os dias? }\end{array}$ & 0 & 1 & 2 & 3 \\
\hline 4. Seu(a) filho(a) tem que fazer força para fazer cocô? & 0 & 1 & 2 & 3 \\
\hline $\begin{array}{l}\text { 5. Com que frequência seu(a) filho(a) só vai ao banheiro fazer } \\
\text { xixi uma ou duas vezes por dia? }\end{array}$ & 0 & 1 & 2 & 3 \\
\hline $\begin{array}{l}\text { 6. Seu(a) filho(a) segura o xixi cruzando as pernas, agachando } \\
\text { ou dançando? }\end{array}$ & 0 & 1 & 2 & 3 \\
\hline $\begin{array}{l}\text { 7. Quando seu(a) filho(a) precisa fazer xixi tem que ir rápido ao } \\
\text { banheiro? (não consegue esperar) }\end{array}$ & 0 & 1 & 2 & 3 \\
\hline 8. Seu(a) filho(a) tem que fazer força para fazer xixi? & 0 & 1 & 2 & 3 \\
\hline 9. Seu(a) filho(a) disse que sente dor quando faz xixi? & 0 & 1 & 2 & 3 \\
\hline $\begin{array}{l}\text { 10.Seu(a) filho(a) passou por alguma situação estressante como } \\
\text { as dos exemplos abaixo nos últimos } 30 \text { dias? }\end{array}$ & & & & \\
\hline $\begin{array}{ll}\text { Marque ao lado sim ou não. } \\
\text { - } & \text { Bebê novo em casa } \\
\text { - } & \text { Mudança de casa } \\
\text { - } & \text { Mudança de escola } \\
\text { - } & \text { Aboblemas escolares } \\
\text { - } & \text { Problemas em casa (divórcio/morte) } \\
\text { - } & \text { Eventos especiais (aniversário) } \\
\text { - } & \text { Acidente / ferimento } \\
\text { - } & \text { Outros }\end{array}$ & & Não (0) & $\operatorname{Sim}(3)$ & \\
\hline
\end{tabular}


Appendix 1 - Original dysfunctional voiding symptom score.

\begin{tabular}{lccccc}
\hline Over the Last Month & $\begin{array}{c}\text { Almost } \\
\text { Never }\end{array}$ & $\begin{array}{c}\text { Less than } \\
\text { Half the } \\
\text { Time }\end{array}$ & $\begin{array}{c}\text { About } \\
\text { Half the } \\
\text { Time }\end{array}$ & $\begin{array}{c}\text { Almost } \\
\text { Every } \\
\text { Time }\end{array}$ & $\begin{array}{c}\text { Not } \\
\text { Available }\end{array}$ \\
\hline $\begin{array}{l}\text { 1 - I have had wet clothes or wet underwear during the } \\
\text { day. }\end{array}$ & 0 & 1 & 2 & 3 & NA \\
2 - When I wet myself, underwear is soaked. & 0 & 1 & 2 & 3 & NA \\
3 - I miss having a bowel movement every day. & 0 & 1 & 2 & 3 & NA \\
$\begin{array}{l}\text { - I have to push for my bowel movements to come } \\
\text { out. }\end{array}$ & 0 & 1 & 2 & 3 & NA \\
5 - I only go to the bathroom one or two times each & 0 & 1 & 2 & 3 & NA \\
day. & & & & 3 & NA \\
6 - I can hold onto my pee by crossing my legs, squatting \\
or doing the "pee dance".
\end{tabular}

\section{COMMENTS}

This study provides the first adaptation into the Brazilian context of a specific instrument for the voiding dysfunction in children. To date, there is no consensus in the literature regarding the best strategy to perform transcultural adaptations. The process chosen was based on the script proposed by Guilemin et al. (8). In addition, this method has been already successfully applied in Brazil by other researchers.

At the present time, there are a great number of questionnaires developed on a certain culture. The process of translation and cultural adaptation has been considered essential for comparisons between studies from different countries, languages, and cultures. A good linguistically accurate translation is not sufficient because items must also be adapted culturally to preserve the conceptual meaning of the questionnaire.

The translations should be mainly evaluated in terms of conceptual equivalence so that necessary grammatical changes can be conceptually similar to another culture. With regard to the cross-cultural adaptation, cultural factors such as habits and activities of a population should be considered because an 
activity which is not common in a certain population can make the instrument's adaptation invalid. In the present study, no obstacles were found either in the Brazilian Portuguese language or regarding the cultural aspects which could render unviable the applicability of the translation and the cross-cultural adaptation of the analyzed instrument.

The cross-cultural adaptation process of the Dysfunctional Voiding Symptom Score to BrazilianPortuguese language followed standardized guides: translation, synthesis, back-translation, Expert Committee, and pre-testing $(7,8)$.

The evaluation of the reliability showed satisfactory internal consistency as indicated by a Cronbach's alpha coefficient of 0.76 for the test and 0.77 for the retest.

The changes made on the adapted version were authorized by the author of the original instrument after previous consultation.

After all the stages had been achieved, the entire process of the cross-cultural adaptation was considered completed.

However, this study did not include the assessment of measurement equivalence. Therefore, further studies should perform this task comparing the psychometric properties of the Portuguese version of the DVSS to those of the original instrument.

\section{CONCLUSION}

The cross-cultural adaptation process of the Dysfunctional Voiding Symptom Score questionnaire to be used on Brazilian children was successfully completed following internationally accepted methodologies.

\section{CONFLICT OF INTEREST}

None declared.

\section{REFERENCES}

1. Feldman AS, Bauer SB: Diagnosis and management of dysfunctional voiding. Curr Opin Pediatr. 2006; 18: $139-47$.
2. Swithinbank LV, Carr JC, Abrams PH: Longitudinal study of urinary symptoms in children. Longitudinal study of urinary symptoms and incontinence in local schoolchildren. Scand J Urol Nephrol Suppl. 1994; 163: 67-73.

3. Hoebeke P, Van Laecke E, Van Camp C, Raes A, Van De Walle J: One thousand video-urodynamic studies in children with non-neurogenic bladder sphincter dysfunction. BJU Int. 2001; 87: 575-80.

4. Nevéus T, von Gontard A, Hoebeke P, Hjälmås K, Bauer S, Bower W, et al.: The standardization of terminology of lower urinary tract function in children and adolescents: report from the Standardisation Committee of the International Children's Continence Society. J Urol. 2006; 176: 314-24.

5. Lordêlo P, Soares PV, Maciel I, Macedo A Jr, Barroso U Jr: Prospective study of transcutaneous parasacral electrical stimulation for overactive bladder in children: long-term results. J Urol. 2009; 182: 2900-4.

6. Farhat W, Bägli DJ, Capolicchio G, O'Reilly S, Merguerian PA, Khoury A, et al.: The dysfunctional voiding scoring system: quantitative standardization of dysfunctional voiding symptoms in children. J Urol. 2000; 164: 1011-5.

7. Beaton DE, Bombardier C, Guillemin F, Ferraz MB: Guidelines for the process of cross-cultural adaptation of self-report measures. Spine (Phila Pa 1976). 2000; 25: 3186-91.

8. Guillemin F, Bombardier C, Beaton D: Cross-cultural adaptation of health-related quality of life measures: literature review and proposed guidelines. J Clin Epidemiol. 1993; 46: 1417-32.

Accepted after revision:

December 20, 2009

\section{Correspondence address:}

Dr. Adriano A. Calado

Pernambuco State University

Pediatric Urology Section

Rua Arnóbio Marques, 310, Santo Amaro

Recife, PE, 50100-130, Brazil

E-mail: caladourologia@yahoo.com.br 